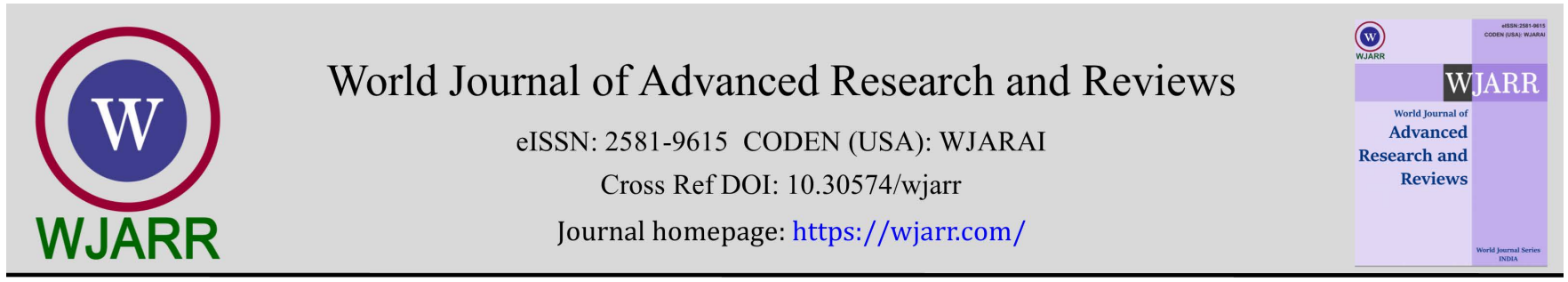

(RESEARCH ARTicle)

\title{
HIV and Malaria co-infection and the impact of viral load and HAART usage on the development of Plasmodium falciparum Artemisinin and Lumefantrine resistant genes in Nnewi, Anambra State, Nigeria
}

\author{
Peace Amaka Onwuzurike ${ }^{1,}{ }^{*}$, Ifeoma Bessie Enweani ${ }^{2}$ and Ifeoma Mercy Ekejindu ${ }^{2}$ \\ ${ }^{1}$ Department of Medical Microbiology and Parasitology, Nnamdi Azikiwe University Teac hing Hospital, Nnewi, Anambra \\ State, Nigeria. \\ 2 Department of Medical Laboratory Science, Nnamdi Azikiwe University, Nnewi, Anambra State, Nigeria.
}

World Journal of Advanced Research and Reviews, 2021, 12(03), 505-516

Publication history: Received on 14 November 2021; revised on 23 December 2021; accepted on 25 December 2021

Article DOI: https://doi.org/10.30574/wjarr.2021.12.3.0710

\begin{abstract}
Background: Human Immunodeficiency virus (HIV) and malaria co-infection poses a serious health threat in subSaharan Africa and other endemic countries. Highly active anti-retroviral therapy (HAART) is currently used to suppress viral loads.

Methods: Blood samples collected from 400 participants comprising 200 HIV sero-positive and 200 sero-negative individuals was added to EDTA sample containers. Malaria parasitemia was evaluated using standard parasitological techniques followed by PCR techniques using the Quick Load One Taq One Step Polymerase Chain Reaction (PCR) for characterization of species of Plasmodium and resistant studies using specific primers. HIV viral load estimation was done using COBAS® TaqMan® Analyzer.
\end{abstract}

Results: Malaria has prevalent rate of $22.75 \%$ in the study population, while the prevalence of malaria infection among the HIV sero-positive and sero-negative is $77.0 \%$ and $23 \%$ respectively. Socio-demographic factors had no significant association with the development of resistant genes. HAART exposed individuals had prevalence of $P f \mathrm{~K} 13$ (6.9\%) and Pfmdr-1 (20.8\%). Viral load was significantly related with the development of resistant genes (100\%) and (86.1\%) for $P f \mathrm{~K} 13$ and $P$ fmdr-1 respectively.

Conclusion: Unsuppressed viral load in HIV sero-positive individuals heightens the prevalence of malaria parasitaemia and increases the chances of possible emergence and spread of PfK13 and Pfmdr-1 genes.

Keywords: HIV; HAART; Plasmodium falciparum; Artemisinin; Lumefantrine

\section{Introduction}

HIV infection and malaria parasitaemia are among the commonest causes of global health challenges in the developing nations, which is estimated to have caused approximately 4 million deaths per year, with HIV increasing the burdensome and severity of malaria [1,2,3]. Malaria parasites are known to trigger the activation of CD4 cells and proinflammatory cells alongside signalling molecules such as cytokines, which in-turn promote favourable scenario for rapid HIV-1 replication in the CD4 cells[2].HIV positive pregnant women have great chances of developing symptomatic malaria, placental malaria and malaria transmission to children [4]. It is not clear if HIV infection can impact resistance

\footnotetext{
${ }^{*}$ Corresponding author: Peace Amaka Onwuzurike

Department of Medical Microbiology and Parasitology, Nnamdi Azikiwe University Teac hing Hospital, Nnewi, Anambra State, Nigeria.

Copyright $(2021$ Author(s) retain the copyright of this article. This article is published under the terms of the Creative Commons Attribution Liscense 4.0.
} 
to anti-malaria drugs such as Artemisinin, which is essentially employed for the treatment of malaria [5]. The recent achievements in the global reduction of the malaria burden are widely challenged by rising resistance to artemisinin and its derivatives [6-10].

Use of artemisinin-based combination therapy (ACT) such as hydroartemisinin-piperaquine has become a drug of choice for the treatment of malaria in the recent years [11]. It was on the premise of the success achieved with ACT that the National Malaria Control Programme declared that malaria would be completely eliminated by 2025, and the declaration has received consummate political support [12]. The emergence of resistant strains of P. falciparum to ACT poses grave threat to the success of this declaration [6]. Mutation of the K13 propeller gene encoding the F3D7/343700 kelch propeller (K13) domain has recently been implicated in artemisinin resistance $[13,14]$. Delay in the clearance of parasites after 3 days of anti-malarial therapy is an indication of resistance [15]. There is also a possibility of partner drug resistance, which is the recurrence of parasitaemia in patients 4-6 weeks after initial malaria parasite clearance [16]. Resistant genes can also modify partner drugs due to polymorphic nature of certain genes e.g. single-nucleotide polymorphisms (SNPs) in P. falciparum chloroquine resistant transporter ( $P f \mathrm{crt}$ ) and $P$. falciparum multi drug resistant1 (Pfmdr1) for amodiaquine increase copy number of the $P$. falciparum multi drug resistant 2 (Pfmdr2) gene for Piperaquine, Pfmdr1 for Mefloquine [17-20]. It is also speculated that the abundance of multidrug resistant gene, Pfmdr1 culminate with rise in Lumefantrine inhibition [17, 21,22].

\section{Methods}

A population of 200 HIV-positive and 200 HIV-negative individuals all of which were 18months and above of age, attending clinics at Nnamdi Azikiwe University Teaching Hospital were recruited for the study. The ethical approval was obtained from the hospital's ethics committee with the approval number: NAUTH/CS/66/VOL.12/199/2019/055. The study population was divided into 2: Group A comprised of 200 HIV positive individuals on Highly Active AntiRetroviral Treatment (HAART) and Group B comprised of 200 HIV negative individuals. Written consent was obtained from all the participants. Blood samples were collected, separated and processed following standard laboratory practices. Out of $4 \mathrm{~mL}$ of blood collected from the veins of participants, $2 \mathrm{~mL}$ were dispensed into a container of EDTA and mixed thoroughly. Bioline rapid diagnostic test (RDT) kit was used for malaria assay. Thick blood film was made for malaria parasite microscopy following WHO standard procedure. The viral load count for HIV positive subjects was done using the remaining part of the first $2 \mathrm{ml}$ volume of anti-coagulated blood previously collected for HIV sero-positive individuals. The second $2 \mathrm{ml}$ of blood was used for molecular identification of the malaria parasite, ACT resistant studies.

\subsection{Preparation of Thick Blood Film}

A drop of each of the well mixed blood samples were placed on the Centre of a clean grease free microscope glass slide (Malaria Diagnostic Workshop, 2010). A glass spreader was used to spread the blood in small circular form. The slide was kept to air dry. The blood films were stained with $3 \%$ Giemsa for $10 \mathrm{mins}$, slides were then allowed to air dry.

Each of the overnight well dried thick film was placed back to back on the staining rack. Each slide was carefully flooded with three percent (3\%) solution of the Giemsa stain made by adding $3 \mathrm{ml}$ of the stock solution to $97 \mathrm{ml}$ of water buffered to $\mathrm{pH} 7.2$ and allowed to stain for $10 \mathrm{mins}$. Clean water was gently poured on one end of the slide keeping off the film to avoid the film floating off the slide while washing off the stains. The washed slides were placed one by one with the film side facing downwards on a dry rack to dry and examined with x100 objective.

\subsection{Detection of antibodies to HIV-1 and HIV-2}

HIV serology was carried out using the current national algorithm for HIV sero-diagnosis. This involved the use of 3 rapid diagnostic kits, following their manufacturer's instructions. Briefly, each patient serum was screened for the presence of HIV antibodies using Determine ${ }^{\circledR}$ (Abott laboratories-kobe Japan). Serum which were negative to HIV antibodies, were considered negative for HIV. However, if it is positive for HIV antibodies, a second kit- Uni-gold (Trinity Biotech Plc, Bray, Ireland) was used. If the result of the second kit agrees with that of the first kit, the patient will be considered to be positive for HIV 1 and 2, but if it disagrees, Stat - Pak ${ }^{(R)}$ (Chembio Diagnostic System USA) was used. The HIV sero-status of the patient was taken as a result of the third kit, either positive or negative.

\subsection{Rapid Diagnostic Test (RDT)}

P. falciparum antigen detection kit (Antech Diagnostics Limited, UK) was used for diagnosis according to the manufacturer's instruction. Two hundred microliters $(200 \mu \mathrm{l})$ of the sample, BioFluid and cell buffer (red) were added the micro tube alongside twenty microliters $(20 \mu \mathrm{l})$ of Proteinase K stock solution. The preparation was mixed thoroughly by voltexing and incubated at $55^{\circ} \mathrm{C}$ for $10 \mathrm{~min}$. Equal volume of the genomic binding buffer was added to the 
digested sample and vortexed for 10 seconds. The mixture was transferred to Zymo-Spin® II-xlr column in a collection tube, centrifugation was done at $12.000 \mathrm{x}$ g for one minute, and the collection tube alongside flow through was discarded. Four hundred microliters $(400 \mu \mathrm{l})$ DNA Pre-wash buffer was added into the spin column of a new collection tube, centrifuged at $12,000 \mathrm{x}$ g for one minute. the collection tube was emptied. Seven hundred microliters (700 $\mu \mathrm{l}) \mathrm{g}$ DNA wash buffer was added to the spin column and centrifuge at 12,000x g for one minute. This step was repeated with two hundred microliters $(200 \mu \mathrm{l})$ g-DNA wash buffer. The collection tube was discarded with the flow through. Spin column was transferred to a new micro-centrifuge tube with $50 \mu$ l DNA Elution Buffer into the matrix and incubated for 5 minutes at room temperature followed by centrifugation at maximum speed for one minute to elute the DNA

\subsection{Polymerase Chain Reaction (PCR) Protocol for Plasmodium Species}

Quick load One Taq one step PCR master (2X) with catalog number NEB M0486S was purchased from lnqaba Biotech Hartfield South Africa incorporated and used according to the manufacturer's instruction. Details of the primers used are stated below. The system components were thawed and mixed by inverting ten times. The PCR was performed in $50 \mu \mathrm{l}$ reaction mixture containing $25 \mu \mathrm{l}$ Quick Load One Taq one- step PCR master mix ( $2 \mathrm{x}), 1 \mu \mathrm{L}$ of each gene-specific forward primer $(10 \mu \mathrm{M}), 1 \mu \mathrm{L}$ of each specific reverse primer $10 \mu \mathrm{M}), 13 \mathrm{ml}$ of nuclease free water and $10 \mu \mathrm{l}$ of DNA template was added last. The PCR was started immediately as follows: Initial denaturation at $94^{\circ} \mathrm{C}$ for $1 \mathrm{minute}$, denaturation at $94^{\circ} \mathrm{C}$ for 30 secs, annealing at Tm-5 for $30 \mathrm{secs}$, extension at $72^{\circ} \mathrm{C}$ for 1 minute, Go to the denaturation step for 39 cycles, final extension at $72^{\circ} \mathrm{C}$ for $15 \mathrm{mins}$ and final holding at $4^{\circ} \mathrm{C}$.

Table 1 Primers used in detection of Plasmodium species

\begin{tabular}{|l|l|}
\hline Primer Name & Primer Sequence \\
\hline rMAL 1: & 5'-ATA ACA TAG TTG TAC GTT AAG AAT AAC CGC-3' \\
\hline rMAL 2: & 5'-AAA ATT CCC ATG CAT AAA AAA TTA TAC AAA-3' \\
\hline rOVA 1: & 5'-ATC TCT TTT GCT ATT TTT TAG TAT TGG AGA-3' \\
\hline rOVA 2: & 5'-ATC TAA GAA TTT CAC CTC TGA CAT CTG-3' \\
\hline rFAL 1: & 5'-TTA AAC TGG TTT GGG AAA ACC AAA TAT ATT-3' \\
\hline rFAL 2: & 5'-ACA CAA TGA ACT CAA TCA TGA CTA CCC GTC-3' \\
\hline rVIV 1: & 5-CGC TTC TAG CTT AAT CCA CAT AAC TGA TAC-3' \\
\hline rVIV 2: & 5' ACT TCC AAG CCG AAG CAA AGA AAG TCC TTA-3' \\
\hline
\end{tabular}

Table 2 Resistance primers

\begin{tabular}{|l|l|l|c|}
\hline Primer name & code & primary sequence & Expected yield \\
\hline Pfmdr-1 F & S2270 & TGCATCTATAAAACGATCAGACAAA & 25 \\
\hline Pfmdr-1R & S2271 & TCGTGTGTTCCATGTGACTGT & 21 \\
\hline K13-F & S226E & GCCTTGTTGAAAGAAGCAGA & 20 \\
\hline K13-R & S226R & GCCAAGCTGCCATTCATTTG & 20 \\
\hline
\end{tabular}

\subsection{Electrophoresis of PCR products}

One-point zero percent Agar-rose gel (1.0\%) was prepared by dissolving $1.0 \mathrm{~g}$ in 100ml Tris EDTA Buffer. The mixture was then heated in a microwave for 5 minutes to dissolve completely. It was then allowed to cool at $56^{\circ} \mathrm{C}$ and $6 \mathrm{ul}$ of Ethidium bromide was added to it. The Agar-rose gel was poured into the electrophoresis chambers with gel comb, and allowed to solidify.

Five micro liters of the amplified PCR products was analyzed on 1.5\% Agar-rose gel containing Ethidium bromide in Tris EDTA buffer. Electrophoresis was performed at 90v for 60 minutes. After electrophoresis the PCR products were visualized by Wealth Dolphin Doc UV trans-illuminator and photographed. Molecular weights were calculated using molecular weight standard of the maker. 
The PCR products were cleaned using Exonuclease/Shrimp Alkaline Phosphatase. Exonuclease/Shrimp Alkaline Phosphatase. Master mix was prepared by adding $50.0 \mu \mathrm{l}$ Exonuclease I (NEB M0293) $20 \mathrm{U} / \mathrm{ul}$ and $200.0 \mu \mathrm{l} \mathrm{Shrimp}$ Alkaline Phosphatase (NEB M0371) 1U/ul in a $0.6 \mathrm{ml}$ micro-centrifuge tube. Exonuclease/Shrimp Alkaline Phosphatase Mix of $2.5 \mu \mathrm{l}$ was then added to $10.0 \mu \mathrm{l}$ of PCR Mixture, mixed well and was incubated at $37^{\circ} \mathrm{C}$ for 30 minutes after which the reaction was stopped by heating at $95^{\circ} \mathrm{C}$ for 5 minutes. Purification was done with the ABI V3.1 Big dye kit according to manufacturer's instructions. The labeled products were then cleaned with the ZymoSeq clean-up kit. Sequencing Binding Buffer of $240 \mu \mathrm{l}$ was added to $20 \mu \mathrm{l}$ sequencing reaction which was then transferred to a Zymo-Spin ${ }^{\text {TM }}$ IB-96 plate mounted onto a collection plate. The mixture was centrifuged at 3,000 x g for 2 minutes. Sequencing Wash Buffer of $300 \mu \mathrm{l}$ was added to each well of the plate and centrifuged at $3,000 \mathrm{x} g$ for 5 minutes. Fifteen microliter (15 $\mu \mathrm{l})$ of water was directly added to the column matrix of the filter plate. The ZymoSpin ${ }^{\mathrm{TM}}$ IB-96 plate was placed on top of the supplied 96-Well PCR plate and mount the assembly onto the Collection Plate which was then centrifuged at 3,000 x $\mathrm{g}$ for 2 minutes to elute the DNA.

\subsection{HIV Viral load Estimation}

The COBAS $®$ AmpliPrep/COBAS $®$ TaqMan $®$ HIV-1 Test, v2.0 is based on three major processes: (1) specimen preparation to isolate HIV-1 RNA; (2) reverse transcription of the target RNA to generate complementary DNA (cDNA), and (3) simultaneous PCR amplification of target cDNA and detection of cleaved dual-labeled oligonucleotide detection probe specific to the target. The COBAS $₫$ AmpliPrep/COBAS $®$ TaqMan $\AA$ HIV -1 Test, v2.0 permits automated specimen preparation followed by automated reverse transcription, PCR amplification and detection of HIV-1 target RNA and HIV1 Quantitation Standard (QS) Armored RNA. The Master Mix reagent contains primers and probes specific for both HIV1 RNA and HIV-1 QS RNA developed to ensure equivalent quantitation of group M subtypes of HIV-1 and of HIV-1 group 0 . The detection of amplified DNA is performed using target-specific and QS-specific dual-labeled oligonucleotide probes that permit independent identification of HIV-1 amplicon and HIV-1 QS amplicon. The quantization of HIV-1 viral RNA is performed using the HIV-1 QS. It compensates for effects of inhibition and controls the preparation and amplification processes, allowing a more accurate quantization of HIV-1 RNA in each specimen. The HIV-1 QS is a noninfectious Armored RNA construct that contains HIV sequences with identical primer binding sites as the HIV-1 target RNA and a unique probe binding region that allows HIV-1 QS amplicon to be distinguished from HIV-1 target amplicon. The HIV-1 QS is added to each specimen at a known copy number and is carried through the subsequent steps of specimen preparation, reverse transcription, simultaneous PCR amplification and detection of cleaved dual-labeled oligonucleotide detection probes. The COBAS $\AA$ TaqMan $\AA$ Analyzer or COBAS $®$ TaqMan $® 48$ Analyzer calculated the HIV-1 RNA concentration in the test specimens by comparing the HIV-1 signal to the HIV-1 QS signal for each specimen and control.

\subsection{Data analysis}

The data collected from the socio-demographic and clinical characteristics of the participants were entered into Microsoft Excel version 2016 and analyzed using STATA 16 statistical package 2019.

\section{Results}

Table 3 Prevalence of mono Plasmodium spp infection and mixed Plasmodium spp infection among the study population

\begin{tabular}{|c|c|c|c|c|c|}
\hline Variable & Total & HIV positive (\%) & HIV negative (\%) & $\chi^{2}$ & p-value \\
\hline \multicolumn{6}{|c|}{ Malaria infection } \\
\hline Positive & $91(22.75)$ & $77(84.6)$ & $14(15.4)$ & 56.460 & $<0.001^{*}$ \\
\hline Negative & $309(77.25)$ & $123(40)$ & $186(60.0)$ & & \\
\hline Total & 400 & 200 & 200 & & \\
\hline \multicolumn{6}{|c|}{ Mixed/mono infection } \\
\hline Pf only & $51(12.75)$ & $46(90.2)$ & $5(9.8)$ & & \\
\hline Pvonly & $1(0.25)$ & $1(100)$ & $0(0)$ & 58.113 & $<0.001^{*}$ \\
\hline Mixed Pf/Pv & $39(9.75)$ & $30(77.0)$ & $9(23.0)$ & & \\
\hline Negative & $309(77.25)$ & $123(39.8)$ & $186(60.2)$ & & \\
\hline Total & 400 & 200 & 200 & & \\
\hline
\end{tabular}


The prevalence of mono and mixed malaria parasitaemia among HIV sero- positive and HIV sero- negative individuals is as shown on Table 1. Prevalence of Plasmodium spp in the study population is $22.75 \%$ while that of Plasmodium vivax and Plasmodium falciparum are $0.25 \%$ and $12.75 \%$ respectively. The prevalence of Plasmodium mixed infection among the HIV sero-positive and sero-negative is $77.0 \%$ and $23 \%$ respectively. The HIV sero-positive had a significantly higher prevalence of malaria infection than HIV sero negative counterparts $(p<0.001)$.Plates 1 to 2 shows diversities of Plasmodium species among the study participants. Plasmodium species were analyzed through molecular genotyping. Two hundred samples were used for HIV sero-positive individuals and equally 200 samples from the HIV sero-negative individuals. The number of HIV sero-positive individuals with Plasmodium falciparum was 77 and 14 for HIV seronegative individuals, (Plates 1 and 2). While Plasmodium vivax was 32 for HIV sero-positive individuals and 9 for HIV sero- negative individuals. (Tables 3 and 4) There was no infection with either Plasmodium malariae or Plasmodium ovale.

\section{201202203204205206207208209210211212213214 L}

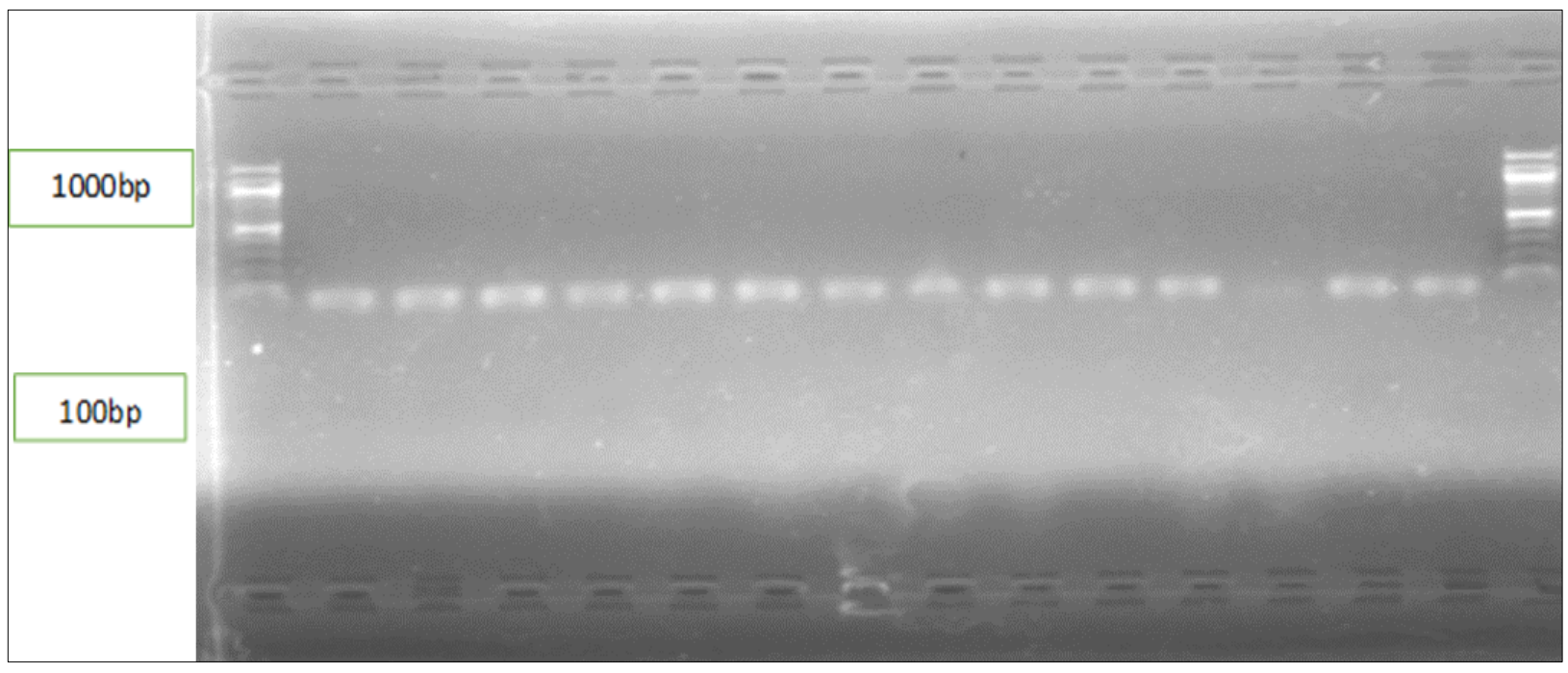

Figure 1 Agar-rose gel bars of expressed Plasmodium falciparum genes analyzed on a $1.0 \%$ agar-rose gel electrophoresis stained with ethidium bromide. L is a 100bp-1000bp DNA ladder (molecular marker). Samples 201, 202, 203, 204, 205,206, 207, 208, 209, 210, 211, 212, 213 and 214 are positive bands for the expressed Plasmodium falciparum genes at 100 bp. for HIV sero-positive individuals

\section{1234567891011121314}

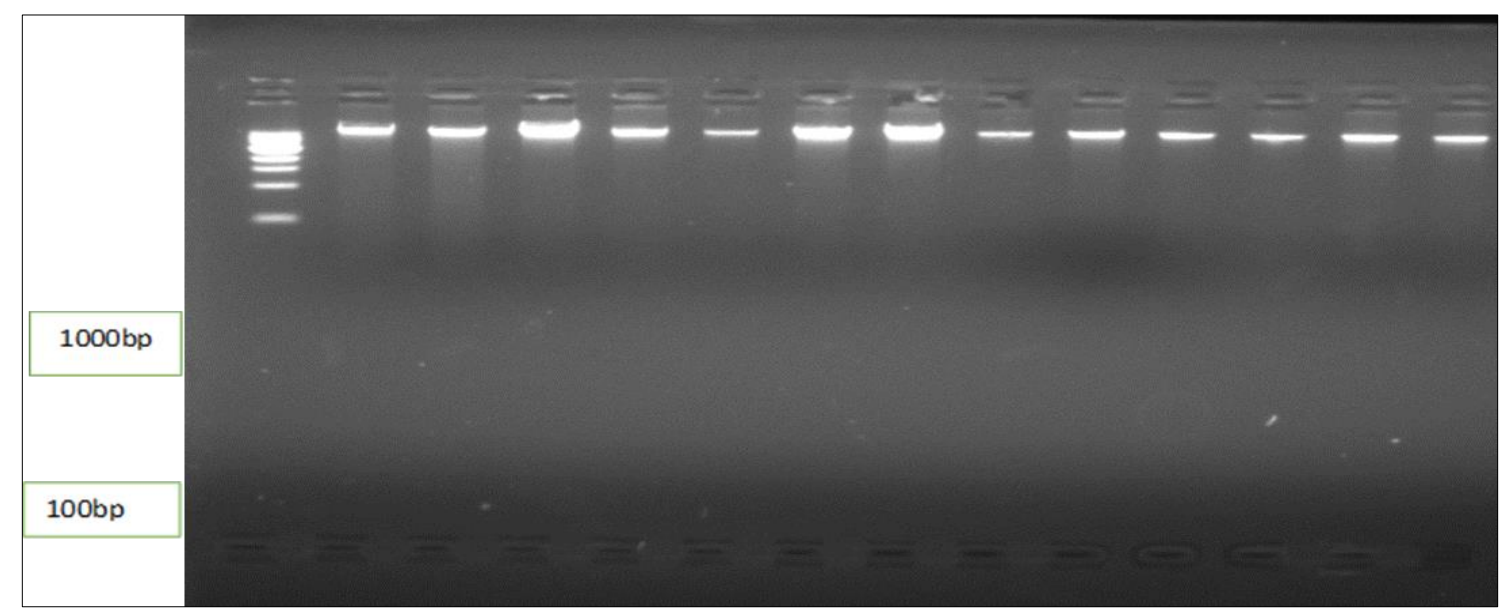

Figure 2 Agar-rose gel bars of expressed Plasmodium falciparum genes analyzed on a $1.0 \%$ agar-rose gel electrophoresis stained with ethidium bromide. L is a 100bp-1000bp DNA ladder (molecular marker). Samples 1, 2, 3, 4, 5, 6 7, 8, 9, 10, 11, 12, 13 and 14 are positive bands for the expressed Plasmodium falciparum genes at 100 bp for HIV sero- negative individuals 


\section{201202203204205206207208209}

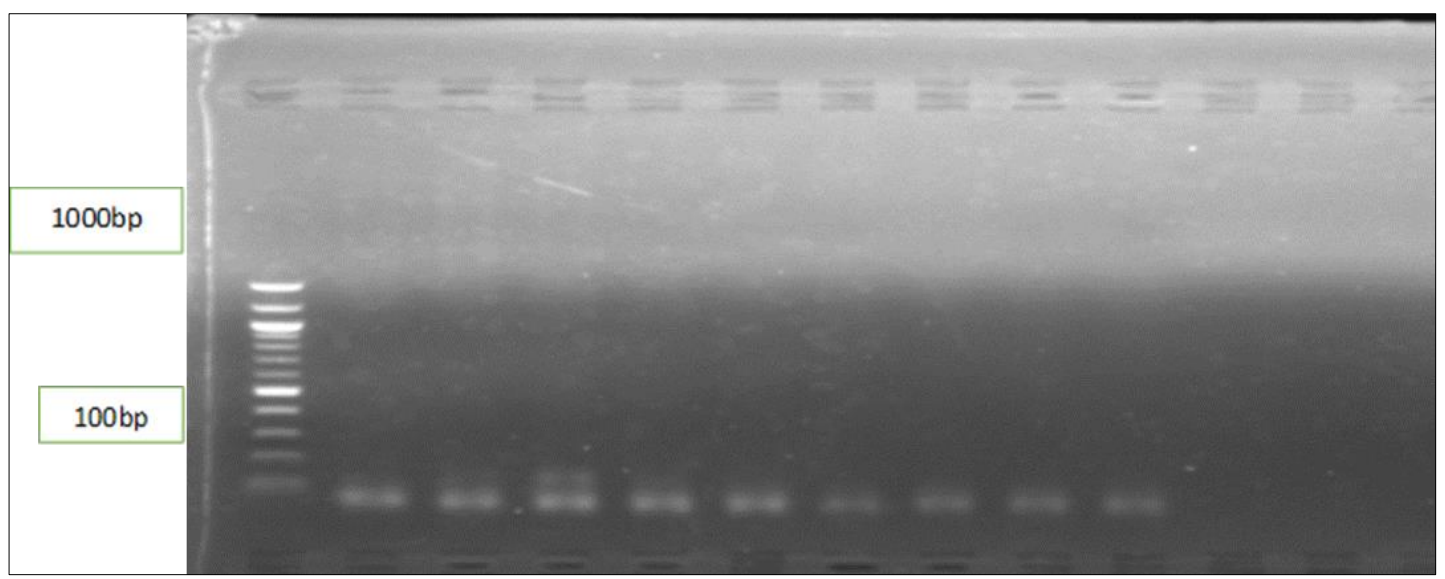

Figure 3 Agar-rose gel bars of expressed Plasmodium vivax genes analyzed on a $1.0 \%$ agar-rose gel electrophoresis stained with ethidium bromide. L is a 100bp-1000bp DNA ladder (molecular marker). Samples 201, 202, 203, 204, 205,206, 207, 208, 209, are positive bands for the expressed Plasmodium vivax genes while 210, 211 and 212 are negative bands for the Plasmodium vivax genes at $100 \mathrm{bp}$ for HIV sero- positive individuals

\section{123456789}

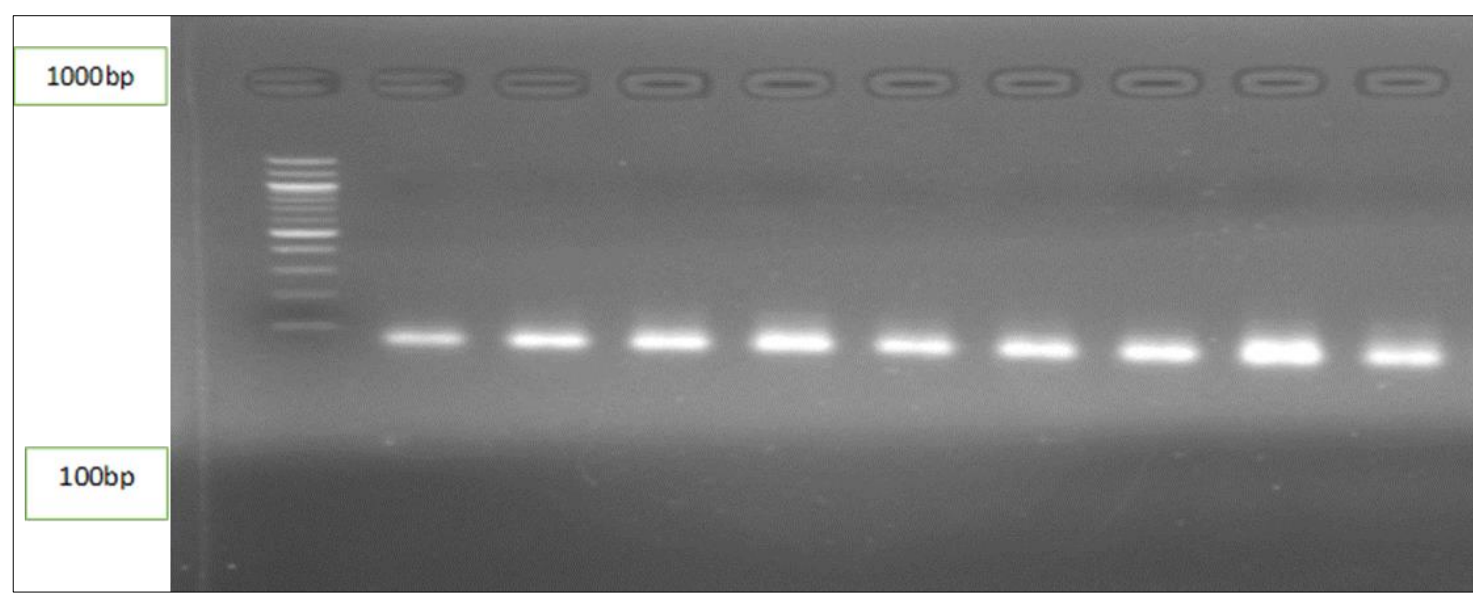

Figure 4 Agar-rose gel bars of expressed Plasmodium vivax genes analyzed on a $1.0 \%$ agarose gel electrophoresis stained with ethidium bromide. L is a 100bp-1000bp DNA ladder (molecular marker). Samples 1, 2, 3, 4, 5, 6, 7, 8, and 9 are positive bands for the expressed Plasmodium vivax at $100 \mathrm{bp}$ for HIV sero- negative individuals

Table 4 and 8 show the effect of HAART usage and duration of usage on the development of Plasmodium falciparum Artemisinin resistant gene (Pfk13), while tables 9 and 10 same effect on Plasmodium falciparum Lumefantrine (Pfmdr1) genes among HIV-malaria co-infected individuals. $100 \%$ of HIV positive individuals exposed to HAART had PfK13 resistant gene while none was present in the HAART naïve group. Although there is no statistical relationship between HARRT usage and $P f K 13$ gene $(p=0.376)$, there is an ox ratio value of 0.879 , which indicate the likelihood that HARRT usage is a risk factor for the development of $P f \mathrm{~K} 13$ gene among HIV sero-positive individuals. There is also insignificant relationship between the time from onset of HARRT intake and the development of $P f \mathrm{~K} 13$ and $P f \mathrm{mdr}-1$ genes $(p=0.293)$ and $(p=0.547)$ respectively.

Table 8 shows the effect of immunity on the development of $P f \mathrm{k} 13$ and $P f$ mdr- 1 genes using viral load as immunological maker. All of the PfK13 genes were recovered from HIV sero-positive individuals whose viral load were unsuppressed while that of $P f \mathrm{mdr}-1$ had $86.05 \%$ occurrence among HIV sero-positive individuals with unsuppressed viral load. There is a statistically significant relationship between the expression of PfK13 gene and Pfmdr- 1 gene and viral load at $(\mathrm{p}=<0.001)$ 
Table 4 Effects of HAART usage on the development of PfK-13 gene among HIV-Malaria co-infected individuals

\begin{tabular}{|l|c|c|c|c|c|}
\hline PfK-13 & Total frequency (\%) & \multicolumn{2}{|l|}{ HAART usage (\%) } & $\chi^{2}$ & $\boldsymbol{p}$-value \\
\hline & & Exposed & Naïve & & \\
\hline Positive & $12(6.0)$ & $12(100)$ & $0(0)$ & 1.992 & 0.376 \\
\hline Negative & $188(94.0)$ & $161(85.64)$ & $27(14.36)$ & & \\
\hline Total & $200(100)$ & $173(100)$ & $27(100)$ & & \\
\hline \multicolumn{7}{|c|}{ Statistically significant, $p$-value $\leq 0.05,0 \mathrm{OR}=0.879(\mathrm{CI}=0.102-3.285)$} \\
\hline
\end{tabular}

Table 5 Effects of HAART duration on the development of PfK13gene among HIV-malaria co-infected individuals

\begin{tabular}{|l|c|c|c|c|c|}
\hline \multirow{2}{*}{ PfK-13 } & \multicolumn{2}{|c|}{ Duration of HAART (\%) } & \multirow{2}{*}{$\chi^{\mathbf{2}}$} & \multirow{2}{*}{ p-value } \\
\cline { 1 - 4 } & $<\mathbf{1 0}$ years & $\mathbf{1 0 - 2 0}$ years & $\mathbf{2 1 - 3 0}$ years & & \\
\hline Positive & $8(66.7)$ & $4(33.3)$ & 0 & 1.725 & 0.293 \\
\hline Negative & $76(47.2)$ & $84(52.0)$ & $1(0.62)$ & & \\
\hline Total & 84 & 88 & 1 & & \\
\hline \multicolumn{7}{|c|}{ Statistically significant, $p$-value $\leq 0.05$ OR= $0.923(\mathrm{CI}=0.846-3.568)$} \\
\end{tabular}

Table 6 Effects of HAART usage on the development of Pfmdr-1 gene among HIV-Malaria co-infected individuals

\begin{tabular}{|l|l|l|l|l|l|}
\hline \multirow{2}{*}{ Pfmdr-1 } & HAART usage (\%) & \multirow{2}{*}{ Total } & $\chi^{2}$ & p-value \\
\cline { 1 - 3 } & Exposed & Naïve & & & \\
\hline Positive & $36(83.72)$ & $7(16.28)$ & 43 & 0.362 & 0.547 \\
\hline Negative & $137(87.26)$ & $20(12.74)$ & 157 & & \\
\hline Total & 173 & 27 & 200 & & \\
\hline \multicolumn{7}{|c|}{ Statistically significant, $p$-value $\leq 0.05$}
\end{tabular}

Table 7 Effects of HAART duration on the development of Pfmdr-1 gene among HIV-malaria co-infected patients

\begin{tabular}{|l|l|l|l|l|l|l|}
\hline \multirow{2}{*}{ Pfmdr-1 } & \multicolumn{2}{|l|}{ Duration of HAART (\%) } & $\begin{array}{l}\text { Total freq } \\
\text { (\%) }\end{array}$ & $\chi^{\mathbf{2}}$ & p-value \\
\cline { 2 - 7 } & $<\mathbf{1 0}$ years & $\mathbf{1 0 - 2 0}$ years & $\mathbf{2 1 - 3 0}$ years & & \\
\hline Positive & $20(55.6)$ & $16(44.4)$ & 0 & 36 & 1.090 & 0.567 \\
\hline Negative & $64(46.7)$ & $72(52.6)$ & $1(0.70)$ & 137 & & \\
\hline Total & 84 & 88 & 1 & 173 & & \\
\hline
\end{tabular}

Table 8 Effect of immunity on the development of Plasmodium falciparum Artemisinin resistant gene (PfK-13) and Plasmodium falciparum Lumefantrine resistant gene Pfmdr-1 using viral load immunological marker

\begin{tabular}{|l|c|c|c|c|c|}
\hline \multirow{2}{*}{ Resistant gene } & \multicolumn{2}{|l|}{ Viral load count } & \multirow{2}{*}{ Total } & \multirow{2}{*}{ p-value } \\
\cline { 2 - 3 } & Suppressed (<1000) & Unsuppressed ( $\mathbf{1 0 0 0})$ & & & \\
\hline K-13 & 0 & $12(100.0)$ & 12 & 52.39 & $<0.001^{*}$ \\
\hline Positive & $161(85.64)$ & $27(14.36)$ & 188 & & \\
Negative & 161 & 39 & 200 & & \\
\hline Total & 161 & & \\
\hline
\end{tabular}


World Journal of Advanced Research and Reviews, 2021, 12(03), 505-516

\begin{tabular}{|l|c|c|c|c|c|}
\hline MDR-1 \\
\hline Positive & $6(13.95)$ & $37(86.05)$ & 157 & 153.70 & $<0.001^{*}$ \\
\hline Negative & $155(86.62)$ & $2(13.38)$ & 43 & & \\
\hline TOTAL & 161 & 39 & 200 & & \\
\hline
\end{tabular}

\section{Discussion}

Malaria and HIV co-infection has potentials of affecting the clinical outcome of each other. The impact of HIV on Malaria includes increase in severity, complications and decreased chances of patient's recovery, while malaria compromises immune system, enabling the rapid replications of HIV [23, 1]. Hence an understanding of how the two infections relate is needed for better and effective management and control of the two disease conditions. The emergence and spread of artemisinin-resistant Plasmodium falciparum from South East Asia (SEA) over a decade now poses a great threat to global malaria elimination and control [24]. The gains also made from the post HAART era in the management of HIV would be dampened should the Artemisinin resistant malaria become a public health issue among HIV sero-positive individuals.

The study population had more of females (69.5\%) participants than male $(30.5 \%)$ and HIV sero -positive (74.9\%) and $(25.1 \%)$ respectively. This is similar to the result by Simon-Oke et al, in a work carried out in Akure, Nigeria where they analyzed the impact of HIV associated immune-suppression on the Plasmodium falciparum chloroquine resistance transporter gene (PfCRT) of HIV individuals and got 28.08\% males and 71.92\% females [25]. More so, a good number of the study participants were observed to be traders $61.39 \%$ with secondary education $47.1 \%$ as the highest level of education. This could be as a result of the geographical region of the study group who are predominantly traders[26].

HIV sero-positive individuals had $22.7 \%$ positivity for malaria parasites. This was lower than $38.5 \%$ and $60.6 \%$ in previous studies obtained in other studies in Nigeria [27, 28]. This variation can be explained by continued gradual decline of the prevalence of malaria as stated in a study by Dawaki et al, possibly due to the scale up of efforts towards prevention of malaria transmission in Nigeria over the years through the use of effective malaria prevention such as the use of insecticide treated mosquito nets and indoor residual spraying [27, 29].

The prevalence of malaria among HIV sero-positive individuals in this study was $84.6 \%$. This agrees with study done by Kwenti, where he studied Malaria and HIV co-infection in sub-Saharan Africa: prevalence, impact, and treatment strategies and found out that the prevalence of malaria among non-pregnant women was between $0.7 \%-47.5 \%$ overall [23]. Notwithstanding, the result is higher than 23.03\%, 27.7\%, 18.9\%, and 7.8\% recorded by Simon-Okeet al,Jegede et al, Onyenekwe et al, and Akinbo et al, respectively in Nigeria [25, 30-32]. It is equally higher; 74.3\%, 47.7\% and 54.2\%, as recorded elsewhere in Nigeria by Dada and Srinivasan, Sanyaolu et al, and Omoti et al, respectively and 61.7\% reported among HIV individuals infected with malaria in Mozambique [33-35].

The observed variation in sero prevalence of malaria among HIV individuals may be due to differences in geographical locations and time lapse between the studies. For instance the Nigerian studies conducted by Sanyaolu et al, Dada and Srinivasan, in South West and Omoti et al, in South -South, Nigeria had varying levels of prevalence [33, 34, 35]. However, the study by Onyenekweet al, though carried out in same geographical region as this study shows a variation in prevalence most likely due to a long difference in year of the analysis and the non-usage of molecular technique which was employed in this study [29].

Molecular genotyping of Plasmodium indicated two species; Plasmodium falciparum and Plasmodium vivax. Plasmodium ovale and Plasmodium malariae species were not detected among the study participants. Among the entire study population, $12.75 \%$ had Plasmodium falciparum infection and only $1.0 \%$ had the Plasmodium vivax species. However, a mixed infection of Plasmodium falciparum and Plasmodium vivax of $9.75 \%$ was recorded. The discovery of Plasmodium vivax in the study not only bears evidence to the presence of Plasmodium vivax in Sub Sahara African countries, it should also provoke public health concern coupled with the need to retrain medical laboratory scientists who easily misdiagnose the infection since its presence was initially considered impossible in the Sub Sahara African countries [36, 37]. The findings of this study agrees with other works done in Cameroon by Howes et al, and Djeunang Dongho et al, and equally in the Southern Nigeria by Oboh et al, that shows incidence of Plasmodium vivax among Duffy coat negative population in Sub-Sahara Africa [47-50]. This is likely due to usage of alternative mechanisms to bind and invade erythrocytes or returning travelers from other regions [38-40] 
By HAART exposure, $100 \%$ of the study participants who were exposed to HAART had Plasmodium falciparum artemisinin resistant gene (PfK13) while none was present in the HAART naïve group. However, 83.72\% prevalence rate was found for Pfmdr-1 among the study participants who were exposed to HAART. The length of time since the commencement of HAART usage also affected the development of the Plasmodium falciparum resistant genes with age group $<10$ years being the highest prevalence of $66.7 \%$ and $55.6 \%$ for $P f \mathrm{~K} 13$ and $P f \mathrm{mdr}-1$ respectively. There is however no significant relationship between the time from onset of HAART intake and the development of PfK13 and Pfmdr-1 genes. This is similar to the study done by Simon-Oke et al, in Akure Nigeria were the impact of HIV-associated immunesuppression on Plasmodium falciparum chloroquine resistance transporter gene (PfCRT) of HIV patients was analysed and $100 \%$ prevalence in patients with CD4count $\leq 200$ was recorded [51]. While Pfmdr-1 had $86.1 \%$ prevalence rate from HIV sero-positive individuals with unsuppressed viral load. Viral load counts have remained one of the strongest correlates and surrogate marker of HIV disease progression regularly used in the clinical setting to monitor the infection. High viral load is a marker for rapid disease progression [41]. This agrees with the assertion of Shoko and Chikobvu, that Viral load and CD4 count can be used to ascertain helpful information needed to improve life expectancy of HIV patients [42].

\section{Conclusion}

There was a higher and significant association between malaria infection and HIV sero-positive individuals alongside a higher prevalence of mono or mixed infection of Plasmodium falciparum and Plasmodium vivax. However, it is noted that usage of HAART and duration of usage of HAART had no significant association on the development of artemisinin resistant gene $P f \mathrm{k} 13$ and Lumefantrine resistant gene $P f \mathrm{mdr}-1$. The viral load of the HIV sero-positive individuals was significantly related to the development of resistant genes and as such this calls for serious concern among HIV seropositive individuals with unsuppressed viral load.

\section{Compliance with ethical standards}

\section{Acknowledgments}

We thank the management of Nnamdi Azikiwe University teaching hospital Nnewi Anambra State Nigeria for giving the approval for this study. Prof. I.M Ekejindu and Prof. I.B Enweani are equally appreciated for supervising this work. Mr. Monday Uchenna Obaji is equaly appreciated for his selfless contribution in the manuscript preparation.

\section{Author's contribution}

Peace Amaka Onwuzurike is the prime investigator. Though the study was conceptualized by Professors Ifeoma Mercy Ekejindu and Ifeoma Bassie Enweani. Peace Amaka Onwuzurike generated the primary data. All authors helped in the validating and processing the raw data while Peace Amaka Onwuzurike prepared the manuscript.

\section{Abbreviations}

Pfmdr-1-Plasmodium falciparum Lumefantrine resistant gene

HAART - Highly active anti-retro-viral therapy

PFK13 - Plasmodium falciparum Artemisinin resistant gene

L- Molecular ladder

HIV - Human Immunosuppressed Virus.

PfCRT- Plasmodium falciparum chloroquine resistance transporter gene

NAUTH -Nnamdi Azikiwe University Teaching Hospital.

\section{Disclosure of conflict of interest}

All authors declare that they have no conflict of interest to disclose.

\section{Statement of ethical approval}

The study protocol was reviewed and approved by the Research Ethics committee of Nnamdi Azikiwe University Teaching Hospital Nnewi Anambra State Nigeria, with the following details: NAUTH/CS/66/VOL.12/199/2019/055.

\section{Statement of informed consent}

Informed consent was obtained from all individual participants included in the study. 


\section{References}

[1] Alemu A, Fuehrer HP, Getnet G, Kassu A, Getie S, Noedl H. Comparison of Giemsa microscopy with nested PCR for the diagnosis of malaria in North Gondar, north-west Ethiopia. Malaria Journal. 2014; 13(1).

[2] Maganda BA, Minzi OMS, Kamuhabwa AAR, Ngasala B, Sasi PG. Outcome of artemether-lumefantrine treatment for uncomplicated malaria in HIV-infected adult patients on anti-retroviral therapy. Malaria Journal. 2014; 13(1).

[3] Ezeoru VC, Enweani IB, Ochiabuto O, Nwachukwu AC. Prevalence of Malaria with anaemia and HIV status inwomen of reproductive age in Onitsha, Nigeria. Journal of Pharmaceutical Research International. 2021; 33(4): 10-19.

[4] Thanh NV, Thuy-Nhien N, Tuyen NTK, Tong NT, Nha-Ca NT, Dong LT, Hien TT. Rapid decline in the susceptibility of Plasmodium falciparum to dihydroartemisinin-piperaquine in the south of Vietnam. Malaria Journal. 2017; 16(1): $1-10$.

[5] Uchechukwu E, Anne N, Babatunde O, Micheal O, Chinyere M, Olanike AU. Prevalence of malaria in HIV positive and HIV negative pregnant women attending antenatal clinics in South Eastern Nigeria. Malawi Medical Journal. 2018; 30(4): 256-261.

[6] Cui L, Mharakurwa S, Ndiaye D, Rathod PK, Rosenthal PJ. Antimalarial drug resistance: Literature review and activities and findings of the ICEMR network. American Journal of Tropical Medicine and Hygiene. 2015; 93: 5768.

[7] Imwong M, Suwannasin K, Kunasol C, Sutawong K, Mayxay M, Rekol H, Dondorp AM. The spread of artemisininresistant Plasmodium falciparum in the Greater Mekong subregion: a molecular epidemiology observational study. The Lancet Infectious Diseases. 2017; 17(5): 491-497.

[8] Talundzic E, Chenet SM, Goldman IF, Patel DS, Nelson JA, Plucinski MM, Udhayakumar V. Genetic analysis and species-specific amplification of the artemisinin resistance-associated kelch propeller domain in P. falciparum and P. vivax. PLoS ONE. 2015; 10(8).

[9] He Y, Campino S, Benavente ED, Warhurst DC, Beshir KB, Lubis I, Clark TG. Artemisinin resistance-associated markers in Plasmodium falciparum parasites from the China-Myanmar border: Predicted structural stability of K13 propeller variants detected in a low-prevalence area. PLoS ONE. 2019; 14(3): 1.

[10] Nyunt MH, Soe MT, Myint HW, Aye MM, Han SS, Kyaw MP. Clinical and molecular surveillance of artemisinin resistant falciparum malaria in Myanmar (2009-2013) NCT02792816 NCT. Malaria Journal. 2017; 16(1): 333.

[11] Tse EG, Korsik M, Todd MH. The past, present and future of anti-malarial medicines. Malaria Journal. 2019; 18: $1-21$.

[12] Kaehler N, Adhikari B, Cheah PY, Von Seidlein L, Day NPJ, Paris DH, Pell C. Prospects and strategies for malaria elimination in the Greater Mekong Sub-region: A qualitative study. Malaria Journal. 2019; 18(1): 203.

[13] Ocan M, Akena D, Nsobya S, Kamya MR, Senono R, Kinengyere AA, Obuku E. K13-propeller gene polymorphisms in Plasmodium falciparum parasite population in malaria affected countries: A systematic review of prevalence and risk factors. Malaria Journal. 2019a; 18: 60.

[14] Ariey F, Witkowski B, Amaratunga C, Beghain J, Langlois A-C, Khim N, Ménard D. A molecular marker of artemisinin-resistant Plasmodium falciparum malaria. Nature. 2014a; 505(7481): 50-55.

[15] Fairhurst RM, Dondorp AM. Artemisinin-Resistant Plasmodium falciparum Malaria. Emerging infections. 2016; 10: 409-429.

[16] Krishna S, Kremsner PG. Antidogmatic approaches to artemisinin resistance: Reappraisal as treatment failure with artemisinin combination therapy. Trends in Parasitology. 2013; 29: 313-317.

[17] Venkatesan M, Gadalla NB, Stepniewska K, Dahal P, Nsanzabana C, Moriera C, Sibley CH. Polymorphisms in Plasmodium falciparum chloroquine resistance transporter and multidrug resistance 1 genes: Parasite risk factors that affect treatment outcomes for P. falciparum malaria after artemether-lumefantrine and artesunateamodiaquine. American Journal of Tropical Medicine and Hygiene. 2014; 91(4): 833-843.

[18] Witkowski B, Amaratunga C, Khim N, Sreng S, Chim P, Kim S, Menard D. Novel phenotypic assays for the detection of artemisinin-resistant Plasmodium falciparum malaria in Cambodia: In-vitro and ex-vivo drug-response studies. The Lancet Infectious Diseases. 2013; 13(12): 1043-1049. 
[19] Amato R, Lim P, Miotto O, Amaratunga C, Dek D, Pearson RD, Fairhurst RM. Genetic markers associated with dihydroartemisinin-piperaquine failure in Plasmodium falciparum malaria in Cambodia: a genotype-phenotype association study. The Lancet Infectious Diseases. 2017; 17(2): 164-173.

[20] Labadie-Bracho M, Adhin MR. Increased pfmdr1 copy number in Plasmodium falciparum isolates from Suriname. Tropical Medicine and International Health. 2013; 18(7): 796-799.

[21] Ljolje D, Dimbu PR, Kelley J, Goldman I, Nace D, Macaia A, Plucinski MM. Prevalence of molecular markers of artemisinin and lumefantrine resistance among patients with uncomplicated Plasmodium falciparum malaria in three provinces in Angola, 2015. Malaria Journal. 2018; 17(1): 1-7.

[22] Mbaye A, Dieye B, Ndiaye YD, Bei AK, Muna A, Deme AB, Ndiaye D. Selection of N86F184D1246 haplotype of Pfmrd1 gene by artemether-lumefantrine drug pressure on Plasmodium falciparum populations in Senegal. Malaria Journal. 2016; 15(1).

[23] Agomo CO, Oyibo WA, Sutherland C, Hallet R, Oguike M. Assessment of markers of antimalarial drug resistance in Plasmodium falciparum isolates from pregnant women in Lagos, Nigeria. PLoS ONE. 2016; 11: 1.

[24] Kwenti TE. Malaria and HIV coinfection in sub-Saharan Africa: prevalence, impact, and treatment strategies. Research and Reports in Tropical Medicine. 2018; 9: 123-136.

[25] Ashley EA, Dhorda M, Fairhurst RM, Amaratunga C, Lim P, Suon S, White NJ. Spread of Artemisinin Resistance in Plasmodium falciparum Malaria.New England Journal of Medicine. 2014; 371(5): 411-423

[26] Simon-Oke IA, Ade-Alao AO, Ologundudu F. The impact of HIV-associated immunosuppression on the Plasmodium falciparum chloroquine resistance transporter gene (PfCRT) of HIV patients in Akure, Nigeria. Bulletin of the National Research Centre. 2020a; 44(1): 156.

[27] Somadina O, Regina A, Chariot O. Semen abnormality and chlamydia trachomatis antibodies among male patients attending fertility clinics in nnewi, anambra state. International Journal of Advanced Research. 2016; 4(9): 11411143.

[28] Dawaki S, Al-Mekhlafi HM, Ibrahim J, Atroosh WM, Abdulsalam AM, Sady H, Lau YL. Is Nigeria winning the battle against malaria? Prevalence, risk factors and KAP assessment among Hausa communities in Kano State. Malaria Journal. 2016; 15: 351.

[29] Houmsou RS, Amuta EU, Sar TT, Adagba. iMedPub Journals Malarial infection among patients attending a Nigerian semi-urban based hospital and performance of HRP-2 pf Rapid diagnostic Test (RDT) in screening clinical cases of Plasmodium falciparum malaria. 2011; 2.

[30] Owoeye DO, Akinyemi JO, Yusuf OB. Decomposition of changes in malaria prevalence amongst under-five children in Nigeria. In Malaria World Journal. 2018.

[31] Jegede FE, Oyeyi TI, Abdulrahman SA, Mbah HA, Badru T, Agbakwuru C, Adedokun O. Effect of HIV and malaria parasites co-infection on immune-hematological profiles among patients attending anti-retroviral treatment (ART) clinic in Infectious Disease Hospital Kano, Nigeria. PLOS ONE. 2017; 12(3): 1.

[32] Onyenekwe CC, Ukibe N, Meludu SC, Ilika A, Aboh N, Ofiaeli N, Onochie A. Prevalence of malaria as coinfection in HIVinfected individuals in a malaria endemic area of southeastern Nigeria. Journal of Vector Borne Diseases. 2007; 44: 250-254.

[33] Akinbo F, Anate P, Akinbo D, Omoregie R, Okoosi S, Abdulsalami A, Isah B. Prevalence of malaria among HIV patients on highly active antiretroviral therapy in Kogi State, North Central Nigeria. Annals of Nigerian Medicine. 2016; 10(1): 11.

[34] Dada EO, Srinivasan S. Prevalence of Malaria and Coinfection with Human ImmunoDeficiency Virus (HIV) in Selected Areas of Ondo State, Nigeria. International Journal of tropical disease and Health. 2015; 8(81): 3439.

[35] Sanyaolu AO, Fagbenro-Beyioku AF, Oyibo WA, Badaru OS, Onyeabor OS, Nnaemeka CI. Malaria and HIV coinfection and their effect on haemoglobin levels from three healthcare institutions in Lagos, southwest Nigeria. African Health Sciences. 2013; 13(2): 295-300.

[36] Omoti CE, Ojide CK, Lofor PV, Eze E, Eze JC. Prevalence of parasitemia and associated immunodeficiency among HIV-malaria co-infected adult patients with highly active antiretroviral therapy. Asian Pacific Journal of Tropical Medicine. 2013; 6(2): 126-130.

[37] Twohig KA, Pfeffer DA, Baird JK, Price RN, Zimmerman PA, Hay SI, Howes RE. Growing evidence of Plasmodium vivax across malaria-endemic Africa. PLOS Neglected Tropical Diseases. 2019; 13(1): e0007140. 
[38] Obare P, Ogutu B, Adams M, Odera JS, Lilley K, Dosoo D, Johnson J. Misclassification of Plasmodium infections by conventional microscopy and the impact of remedial training on the proficiency of laboratory technicians in species identification. Malaria Journal. 2013; 12(1).

[39] Howes RE, Reiner RC, Battle KE, Longbottom J, Mappin B, Ordanovich D, Hay SI. Plasmodium vivax Transmission in Africa. PLoS Neglected Tropical Diseases. 2015; 9(11).

[40] DjeunangDongho GB, Gunalan KL'Episcopia M, Paganotti GM, Menegon M, Sangong RE, Russo G. Plasmodium vivax Infections Detected in a Large Number of Febrile Duffy-Negative Africans in Dschang, Cameroon. The American Journal of Tropical Medicine and Hygiene. 2021; 20(12): 55.

[41] Oboh MA, Singh US, Singh US, Ndiaye D, Badiane AS, Ali NA, Das A. Presence of additional Plasmodium vivax malaria in Duffy negative individuals from Southwestern Nigeria. Malaria Journal. 2020; 19(1).

[42] Dessie ZG, Zewotir T, Mwambi H, North D. Modelling of viral load dynamics and CD4 cell count progression in an antiretroviral naive cohort: Using a joint linear mixed and multistate Markov model. BMC Infectious Diseases. 2020; 20(1): 246.

[43] Shoko C, Chikobvu D. A superiority of viral load over CD4 cell count when predicting mortality in HIV patients on therapy. BMC Infectious Diseases. 2019; 19(1): 169. 